\title{
Nowe wykorzystanie blogów internetowych. Ewolucja w stronę funkcji dydaktycznej
}

\section{KEYWORDS}

blog, educational process, teacher, student

\begin{abstract}
Polcyn-Matuszewska Sylwia Maria, Nowe wykorzystanie blogów internetowych. Ewolucja w stronę funkcji dydaktycznej [The New Uses of Weblogs. Evolving Towards Didactic Functions]. Kultura - Społeczeństwo - Edukacja nr 2(6) 2014, Poznań 2014, pp. 207-220, Adam Mickiewicz University Press. ISBN 978-83-232-2869-1. ISSN 23000422

Nowadays blogs have been acquiring new functions. Apart from traditional blogs, one can see a growing number of blogs that have a didactic function. Blogs have been used more and more often by the teachers at different education levels in order to support and optimise the teaching and learning processes. Linking entertainment and teaching, they have become a place of unlimited possibilities for the students, where students can acquire new knowledge, develop their own interests and increase cognitive curiosity. Educational blogs that are used actively by the teachers can positively influence educational process and introduce students to self-education, thus preparing them to the process of lifelong learning in the future.
\end{abstract}

Przestrzeń Internetu stwarza ogromne możliwości. Współcześnie jest to największa na świecie sieć posiadająca ogromny zasób informacji z różnych dziedzin nauki. Przez badaczy jest ona określana również jako wszechobecne medium, wzajemnie łączące wszystkie komputery oraz ludzi na całym świecie (Hoffman, 1995: 13, za: Bereźnicki, 2011: 208).

Sieć ta $\mathrm{z}$ roku na rok odgrywa coraz większą rolę w edukacji, stając się nieograniczonym źródłem wiedzy i możliwości. Dla uczniów różnych szczebli kształcenia jest ona kluczowym i praktycznie wykorzystywanym narzędziem wspomagającym proces uczenia się, które zaspokaja również u młodych jednostek ich naturalną potrzebę poznawania otaczającego świata oraz komunikowania się z innymi ludźmi. 
Franciszek Bereźnicki określił sieć komputerową jako wszechstronną pomoc dydaktyczną, która jest bogatym źródłem informacji. Głównym jej wyznacznikiem jest zaś to, iż w łatwy i szybki sposób można z niej korzystać w dowolnej chwili i dowolnym miejscu. Taka nieograniczona dostępność przestrzeni wirtualnej umożliwia ciągłą wymianę informacji, ich pozyskiwanie, selekcjonowanie oraz przetwarzanie. Informacje zebrane w przestrzeni Internetu stanowią coraz częściej uzupełnienie wiedzy przekazywanej przez nauczycieli w ramach określonych przedmiotów szkolnych, zaś informacje, które można z niego pozyskać, wybiegają poza standardowe programy nauczania, a przede wszystkim ukazane są w przystępnej dla młodych ludzi formie - multimedialnej (Bereźnicki, 2011: 208). Interesujące, kolorowe grafiki, animacje, filmy, podcasty, znacznie wpływają na zainteresowanie młodej jednostki danym zagadnieniem. Poszerzają jej wiedzę, stają się środkiem podglądowym. Internet nie jest już miejscem spełniającym wyłącznie funkcje rozrywkowe w czasie wolnym dzieci i młodzieży, ale zyskuje coraz większe znacznie w kontekście szeroko ujętej edukacji. Dlatego też niebywale ważnym zadaniem stojącym przed szkołą oraz współczesnym nauczycielem jest wdrażanie młodych ludzi do społeczeństwa informacyjnego, zaznajamianie ich $\mathrm{z}$ nowymi technologiami i sposobami ich wykorzystania w procesie uczenia się oraz samokształcenia. Proces uczenia się powinien być systematycznym, zamierzonym, jak również długotrwałym zbiorem określonych czynności, które są ze sobą powiązane. Uczenie się powinna cechować również planowość, ukierunkowanie na realizację określonego celu, świadomość, a także wielostronna aktywność osoby uczącej się. Samokształcenie natomiast można rozumieć jako opanowanie wiedzy naukowej, a także określonych sprawności w samodzielny sposób, bez ingerencji nauczyciela lub innych podmiotów kontrolujących (zob. Bereźnicki, 1987: 19-28). Jednakże najważniejszą rolę $\mathrm{w}$ procesie nauczania/uczenia się oraz samokształcenia spełnia motywacja wewnętrzna ucznia, która jest jednym $\mathrm{z}$ istotniejszych pojęć w dydaktyce. Motywacja wewnętrzna to potrzeba bądź też chęć pozyskiwania nowej wiedzy, uzupełniania wiedzy już posiadanej, odpowiadania na ważne z punktu widzenia jednostki pytania. Nie jest ona jednak związana z nagrodami, gratyfikacją zewnętrzną, ale odpowiadają za nią głównie zainteresowania własne jednostki, potrzeba poszukiwania oraz poznawania otaczającego świata (Siuda, 2013: 9). Zadaniem nauczyciela jest wzbudzanie w uczniu nie tylko motywacji ukierunkowanej na gratyfikacje zewnętrzne, ale przede wszystkim ukazanie praktycznych walorów motywacji wewnętrznej. Istotną rolę mogą tu odegrać nowe technologie.

Również sam nauczyciel, chcąc podążać za szybkim postępem cywilizacyjnym i wychodzić poza obowiązujące schematy w szkole, powinien aktywne wykorzy- 
stywać w procesie nauczania nowe media i możliwości, jakie oferują, aby wzbogacać własny warsztat pracy i rozwijać własne nowomedialne kompetencje.

Wykorzystanie przez nauczycieli nowych technologii w procesie kształcenia może być odpowiedzią na potrzeby młodych osób, które w przestrzeni wirtualnej poszukują cyberprzyjaciół, spędzają swój wolny czas, dzielą się swoimi pomysłami, osiągnięciami, niepowodzeniami, korzystając z tej formy komunikacji regularnie i coraz częściej.

$\mathrm{Z}$ roku na rok powstaje coraz większa liczba:

1. Stron internetowych

- www.edulandia.pl,

- www.edunews.pl,

- www.edukacjamedialna.edu.pl,

- www.interklasa.pl,

- http://www.teraz-wiedza.pl ${ }^{1}$,

2. Platform

- www.gromar.eu,

- www.upel.agh.edu.pl,

- www.platforma.edu.pl,

- www.eped.pl';

3. For internetowych

- www.forum.liceum36.pl,

- www.forum.edukacja.net,

- www.abcd.edu.pl (zakładka „forum”),

- www.forumszkolne.pl ${ }^{3}$,

których główną tematyką jest szeroko ujmowana edukacja. Są to szczególne miejsca w przestrzeni wirtualnej, z których można czerpać informacje na temat współczesnej szkoły, porażek oraz sukcesów uczniów, programów nauczania na poszczególnych szczeblach edukacji, a także znaleźć liczne przykłady różnych materiałów edukacyjnych, metodycznych, scenariuszy zajęć, gotowych ćwiczeń, gier i filmów dydaktycznych, poradników itp., które stanowią bogatą bazę dla nauczycieli, jak również i dla samych uczniów.

Ogromną popularnością cieszą się również profile edukacyjne, tak zwane fanpage $^{4}$ na portalach społecznościowych. Obecnie można odnaleźć bardzo dużą liczbę

\footnotetext{
${ }^{1}$ Są to przykładowe strony internetowe, których tematyką jest szeroko ujęta edukacja.

${ }^{2}$ Są to przykładowe platformy edukacyjne, których tematyką jest szeroko ujęta edukacja.

${ }^{3}$ Są to przykładowe fora internetowe, których tematyką jest szeroko ujęta edukacja.
} 
stron fanowskich, które eksponują walory edukacyjne lub podejmują bezpośrednio tę tematykę. Najczęściej zamieszczane są na nich odnośniki do innych stron internetowych $\mathrm{z}$ artykułami naukowymi, popularnonaukowymi, doniesieniami $\mathrm{z}$ badań, wywiadami $\mathrm{z}$ nauczycielami, badaczami, a także stron związanych $\mathrm{z}$ edukacją i szkolnictwem na różnych szczeblach. Ponadto, na tych charakterystycznych portalach można odnaleźć treści propagujące wykorzystanie nowych technologii, metod i technik w nauczaniu. Fanpage zawierają również całe galerie zdjęć oraz filmów z różnych uroczystości szkolnych, wydarzeń klasowych, a także eksponują artystyczne oraz literackie prace uczniów. Możliwości ich wykorzystania w edukacji jest wiele.

Coraz większą popularność zarówno wśród dzieci, młodzieży, jak i osób dorosłych, zyskują także blogi internetowe, które z początku pełniły rolę wyłącznie internetowych pamiętników, współcześnie zaś stają się narzędziem dydaktycznym coraz chętniej wykorzystywanym przez nauczycieli, którzy chcą wzbogacić i zoptymalizować sam proces kształcenia. Blogi umożliwiają również połączenie dwóch ważnych elementów w rozwoju młodego człowieka: nauki oraz rozrywki (Siuda, 2013: 10).

Zgodnie z literaturą przedmiotu, proces kształcenia, czyli proces obejmujący zarówno nauczanie, jak i uczenie się, rozumiany jest jako uporządkowany ciąg zdarzeń obejmujący czynności leżące po stronie tak nauczyciela (nauczanie), jak i uczniów (uczenie się). Jest on ukierunkowany przede wszystkim przez odpowiedni dobór celów i treści przez nauczyciela oraz takie warunki i środki, które mają służyć wywołaniu określonych zmian w uczniach, a które są zgodne z przyjętymi celami kształcenia (Okoń, 1987: 133, za: Bereźnicki, 2011: 13).

Blogi internetowe spełniają współcześnie również jeszcze jedną ważną funkcję, a mianowicie stały się one coraz częściej praktykowaną nową formą komunikacji pomiędzy nauczycielem a uczniem przy wykorzystaniu komputera oraz łącza internetowego (Wawrzak-Chodaczek, 2008: 200). Ponadto, są one w coraz większym stopniu wykorzystywane do pozyskiwania szeregu różnych aktualnych oraz praktycznych informacji, których celem jest wzbogacenie procesu nauczania/uczenia się i samokształcenia uczniów. Blogi w XXI wieku stają się ważnym elementem edukacji zarówno dzieci, młodzieży, jak również i osób dorosłych.

Blog, zgodnie z funkcjonującą $\mathrm{w}$ literaturze przedmiotu definicją, można określić jako pamiętnik, w którym autor przy użyciu komputera oraz sieci internetowej

\footnotetext{
${ }^{4}$ Fanpage (ang.) - specjalnie stworzona na portalu społecznościowym Facebook strona fanowska.
} 
opisuje i dzieli się z innymi użytkownikami/czytelnikami swoimi doświadczeniami, przeżyciami dnia codziennego, zainteresowaniami, a także przemyśleniami $\mathrm{w}$ różnych kwestiach, czyniąc to $\mathrm{w}$ miarę regularnie. Nic więc dziwnego, iż obecnie blogi internetowe określane są mianem internetowych pamiętników. Autorzy tej formy ekspresji dzielą się swoimi powszednimi doświadczeniami, uczuciami, emocjami, sukcesami, porażkami w życiu osobistym i/lub zawodowym, opisują drogę do pracy, szkoły, recenzują książki, filmy, gry komputerowe, sami tworzą opowiadania, wiersze lub prezentują inne formy twórczości własnej.

Współcześnie blogi poruszają bardzo różną tematykę. Dotyczą m.in. kulinariów, rodziny, miłości, sportu, życia codziennego, gier tradycyjnych i komputerowych, pasji, motoryzacji, społeczeństwa, kultury, dzieci, nastolatków, dorosłych, seniorów itp. Ponadto, dotyczą takich aspektów życia ludzkiego, jak: związki, problemy, rodzina, przyjaźń, codzienność, praca, dzieci, seks, edukacja, kariera zawodowa, rozwój osobisty. Opisują szereg różnych emocji: miłość, szczęście, smutek, ból, samotność, nadzieję, stany depresyjne. Obejmują również aspekty związane z wiarą i wartościami transcendentalnymi: Bogiem, miłością, nadzieją, człowiekiem, śmiercią ${ }^{5}$ Dzięki takiemu wachlarzowi różnych kategorii (zwanych etykietami, tagami), czytelnik może $\mathrm{z}$ łatwością odnaleźć wiele interesujących wpisów i wątków zgodnych z jego własnymi zainteresowaniami.

Blogi internetowe stały się współcześnie również ogromną siecią, wzajemnie ze sobą połączoną. Dzięki temu ich autorzy bez żadnego problemu mogą między sobą wymieniać opinie, komentarze na określony temat, umieszczać hiperłącza, odnośniki do interesujących filmów, słuchowisk i stron internetowych podejmujących podobną problematykę. Takie możliwości spowodowały powstanie tak zwanej blogosfery, która określana jest w literaturze naukowej jako społeczność bądź sieć społeczna wzajemnie powiązanych z sobą blogów. Blogosfera określana jest także przez badaczy jako zjawisko społeczne, wokół którego powstaje coraz większa liczba badań naukowych ${ }^{6}$.

Zainteresowanie blogami wzrasta $\mathrm{z}$ roku na rok, nie tylko dzięki możliwości czytania ciekawych wpisów innych użytkowników, ale przede wszystkim dzięki możliwości wzajemnego komunikowania się, czy także pozostawiania własnych komentarzy, podtrzymywania i nawiązywania nowych kontaktów oraz powstawania ogólnie ujętych więzi społecznych. Blogi można zatem określić jako medium dwustronne, które umożliwia m.in. ciągłą wymianę informacji pomiędzy odbiorca-

\footnotetext{
${ }^{5}$ Rodzaje wymienionych kategorii na podstawie www.blog.pl.

${ }^{6}$ Więcej: http://pl.wikipedia.org/wiki/Blogosfera (dostęp: 03.01.2014 r.).
} 
mi i nadawcami tworzącymi oraz prezentującymi konkretne treści (zob. Wawrzak-Chodaczek, 2008: 200-201, 205, 209).

O popularności blogów w Polsce świadczą również dane prezentowane przez największe platformy blogowe.

Do połowy 2012 roku postała następująca liczba blogów internetowych:

- na platformie Blog.onet.pl - 1797758 blogów,

- na platformie Bloog.pl - 941441 blogów,

- na platformie Znajomi.pl - 388001 blogów,

- na platformie Blox.pl - 295604 blogów,

- na platformie Blogi.moje.pl - 31074 blogów7

Łącznie daje to 3453878 blogów, które podejmują najróżniejszą tematykę, a ich autorami są różni ludzie. Do tej pory liczba blogów mogła się nawet podwoić, niestety, w przestrzeni wirtualnej brakuje danych na rok 2013.

Tak ogromna liczba blogów świadczy o ich prostocie oraz łatwości użytkowania. Korzystanie z blogów internetowych nie jest bowiem skomplikowane, dlatego też czynią to ludzie w różnym wieku, od dzieciństwa aż do późnej starości. Przejrzyste funkcje bloga ułatwiają jego zakładanie, codzienne korzystanie, publikowanie wpisów, załączanie filmów, dźwięków, animacji, kolorowych grafik, komunikowanie się z innymi użytkownikami, łączenie blogów w swoistego rodzaju sieć, a także dostosowanie ich wyglądu do osobistych i indywidualnych preferencji autora, tak zwanego blogera, za pomocą gotowych już szablonów. Brak skomplikowanej struktury, łatwość obsługi oraz chronologiczny układ wpisów autora ${ }^{8}$ powodują, iż stają się one praktycznym narzędziem wykorzystywanym przez dzieci, młodzież, a nawet i osoby dorosłe.

Autorami blogów stają się nie tylko uczniowie, studenci, politycy czy gwiazdy show-biznesu, ale coraz częściej też nauczyciele i wykładowcy szkół wyższych, którzy chcą wzbogacić własny warsztat pracy i zachęcić uczniów do aktywnego uczestnictwa w procesie kształcenia. Głównym zaś motywem prowadzenia blogów przez tak różne grupy społeczne o różnym statusie materialnym i wykształceniu jest chęć wyrażenia własnych myśli, uczuć i emocji, pasji, własnych zainteresowań, chęć nawiązywania i podtrzymywania kontaktów ze znajomymi, szerzenia treści edukacyjnych, naukowych, a także i zawodowych.

${ }^{7}$ M. Jeleśniański, Liczba blogów w Polsce i na świecie - czy da się ja określić?; http://eredaktor.pl/ internet-badania-trendy/liczba-blogow-w-polsce-i-na-swiecie-czy-da-sie-ja-okreslic/ (dostęp: 03.01.2014 r.).

${ }^{8}$ Z. Meger, Nowe narzędzia edukacyjne $w$ sieciach społecznościowych; http://www.e-edukacja.net/ osma/referaty/Sesja_2b_2.pdf (dostęp: 05.01.2014 r.). 
W Internecie powstaje również coraz większa liczba blogów, które ze względu na zamieszczane przez autora treści można określić jako:

- fotoblogi - przeważającą częścią wpisów są różnego rodzaju zdjęcia;

- audioblogi - dominującym elementem na blogu są nagrania dźwiękowe;

- videoblogi - we wpisach przeważają filmy

Współcześnie blogi stwarzają ogromne możliwości. To od pomysłowości ich autora, a także jego własnych zainteresowań zależy ostateczny kształt bloga.

Analizując jednak rolę blogów internetowych we współczesnym świecie, nie można również zapomnieć o ich głównych funkcjach, które zaczęły powstawać i kształtować się wraz z rozwojem tej formy internetowej wypowiedzi. Współcześnie blogi spełniają następujące funkcje:

- informacyjną,

- rozrywkową,

- komunikacyjną,

- opiniotwórczą,

- marketingową,

- integrującą,

- edukacyjną (Wawrzak-Chodaczek, 2008: 205).

Ta ostatnia funkcja jest natomiast coraz częściej realizowana w środowisku uczniowskim i nauczycielskim.

Blog, jako atrakcyjne - z punktu widzenia dzieci i młodzieży - medium, może stać się ciekawym urozmaiceniem lekcji, nowoczesnym narzędziem dydaktycznym, które wzbogaca i optymalizuje proces kształcenia, przyspiesza proces opanowywania przez uczniów nowej wiedzy i poszerzania oraz systematyzowania wiedzy już zdobytej. Blog może też w przyszłości odgrywać znaczącą rolę w samokształcenia młodych osób.

Blog internetowy, jako dwustronne medium komunikacyjne, pole wymiany myśli pomiędzy nauczycielem a uczniami, stwarza możliwość lepszego poznawania uczniów oraz odpowiadania na ich indywidualne oraz zbiorowe potrzeby. Nauczyciel - oprócz możliwości korzystania z bloga jako tablicy informacyjnej, na której umieszcza rozkład zajęć, plan pracy, zasady oceniania i zaliczania określonego przedmiotu, treści zadań domowych i zdań dodatkowych - stwarza możliwość podjęcia ciekawych dyskusji w obrębie omawianych tematów na lekcji i tym samym przenieść je poza mury szkoły ${ }^{10}$. Dla uczniów jest to atrakcyjne, gdyż nie są

\footnotetext{
${ }^{9}$ Ibidem.

${ }^{10} \mathrm{~J}$. Hendzel, Uczymy się blogując?, „e-mentor” 2007, nr 4(21), wydanie internetowe: http://www.ementor.edu.pl/artykul/index/numer/21/id/455 (dostęp: 03.01.2014 r.).
} 
oni związani i wpisani w konkretną, tradycyjną oraz sztywną rolę, ale czują się przede wszystkim bardziej swobodnie i mniej formalnie. Stwarza to możliwość kreowania bardziej twórczych opinii, pomysłów i sądów na dany temat. Ponadto, jest to ogromna szansa dla uczniów, którzy odczuwają lęk przed ekspozycją społeczną lub są po prostu nieśmiali. Komunikacja za pomocą blogów daje im pewną formę swobody, możliwość przemyślenia swojej wypowiedzi. Takie osoby są również w mniejszym stopniu narażone na negatywne emocje oraz krzywdzące opinie ze strony grupy rówieśniczej. Blog umożliwia ponadto uczniom zaprezentowanie się szerszemu gronu publiczności, rodzinie, znajomym lub innym zaprzyjaźnionym osobom z całej Polski, a nawet i całego świata. Świadomość, iż treści, które są publikowane na blogu, mogą dotrzeć do wielu ludzi i są niczym nieograniczone w przestrzeni wirtualnej, może wpływać na uczniów motywująco, zwłaszcza w kwestii rzetelnego przygotowywania materiałów, treści i wpisów tam zamieszczanych (Siuda, 2013: 9).

Blog może również pełnić rolę integrującą społeczność uczniowską. Nauczyciele bądź sami uczniowie mogą bowiem zamieszczać na nim krótkie sprawozdania ze wspólnych wycieczek, wyjazdów integracyjnych, kronik klasowych, konkursów, zdjęcia oraz filmy z ważniejszych wydarzeń klasowych.

Blog może też spełniać rolę wspomagającą przy nauczaniu trudniejszych, zdaniem uczniów, przedmiotów, np. matematyki. Zaprezentowanie skomplikowanych wzorów matematycznych za pomocą kolorowych grafik, animacji czy filmów multimedialnych może wpływać pozytywnie na przyswojenie przez uczniów nowej wiedzy. Również w innych przedmiotach ścisłych, takich jak fizyka i chemia, blog spełnia doskonale swoje funkcje. Nauczyciele mogą pokazywać tam doświadczenia laboratoryjne, których nie są w stanie wykonać w trakcie lekcji. Takie unaocznienie treści staje się atrakcyjnym sposobem na wzbudzenie ciekawości poznawczej uczniów.

Również nauczyciele przedmiotów humanistycznych mają do dyspozycji wiele możliwości, które oferują te narzędzia internetowe. Mogą dla swoich uczniów, lub przy ich pomocy, tworzyć biblioteki lektur szkolnych, wymieniać się opiniami na ich temat, zamieszczać własne wypracowania, opowiadania, wiersze itp.

Blog może również stać się okazją do poznania swoich uczniów, ich zainteresowań, pasji, oczekiwań. Dobre poznanie własnego ucznia, a przede wszystkim poznanie jego potrzeb edukacyjnych, może być drogą do osiągnięcia przez niego sukcesu edukacyjnego w przyszłości. Ponadto, uczniowie mają bardziej pozytywny stosunek do nauczycieli, którzy „są na czasie”, interesują się nowymi technologiami oraz możliwościami ich wykorzystania. Nauczyciel, który przełamuje tradycyj- 
ne schematy i wychodzi poza tradycyjne metody nauczania, w oczach uczniów jest bardziej „atrakcyjny”.

Blog umożliwia też wielokrotne powracanie do interesujących treści, ich odtwarzanie, grupowanie, a także eksponowanie. Uczeń w dogodnym dla siebie momencie może skorzystać $\mathrm{z}$ informacji, które umożliwią mu pogłębienie uprzednio zdobytej wiedzy, jej utrwalenie lub też powtórzenie. Jest to szczególnie ważne dla usystematyzowania i utrwalenia zdobytej przez ucznia wiedzy, a przede wszystkim zastosowania jej zarówno w teorii, jak i praktyce.

Wykorzystanie na blogu technik multimedialnych - w tym szczególnie dźwięków, tekstu, animacji oraz grafiki - w aspekcie edukacyjnym powoduje powstawanie nieocenionego sposobu wyrazu, który kształtuje aktywną postawę poznawczą wśród młodych jednostek i zachęca ich do zdobywania nowej wiedzy (Bereźnicki, 2011: 209). Możliwości, które oferują blogi, odpowiadają w dużym stopniu na zapotrzebowanie na nową, ciekawszą wiedzę, a przede wszystkim zaprezentowanie tej wiedzy w przystępnej dla uczniów formie. Zadaniem nauczyciela oraz szkoły jest przygotowanie młodych jednostek do szybkich zmian cywilizacyjnych, do promowania kreatywności wśród młodych ludzi, wzbudzania postawy twórczej. Z pewnością takie możliwości oferują współczesne blogi internetowe wraz ze swoimi narzędziami (Siuda, 2013: 9).

Blogi są bardzo często zakładane przez osoby młode, zwłaszcza przez uczniów, dlaczego by więc nie wykorzystać ich „naturalnego środowiska” do ciekawego prowadzenia zajęć? Współczesna szkoła i nauczyciele powinni wychodzić naprzeciw oczekiwaniom młodych ludzi, dostosowywać się do zmian cywilizacyjnych i pokazywać młodym ludziom, jak w najbardziej efektywny sposób można wykorzystywać nowe technologie w procesie uczenia się, a w przyszłości - w procesie samokształcenia (Siuda, 2013: 5-12).

Współcześnie w Internecie można odnaleźć szereg blogów o charakterze edukacyjnym. Pełnią one różne role i są prowadzone w różnych dydaktyczno-wychowawczych celach.

Do jednej z grup blogów, która coraz częściej pojawia się w Internecie i eksponuje wartości edukacyjne, zaliczane są blogi autorstwa nauczycieli, lektorów i specjalistów w określonej dziedzinie, którzy poprzez prowadzenie własnego bloga przekazują konkretną wiedzę i wspomagają nauczanie np. języków obcych. Takie blogi są zazwyczaj prowadzone przez doświadczonego lektora, nauczyciela, który na swoim blogu udostępnia różnego rodzaju materiały, książki, w tym ćwiczenia gramatyczne wraz z odpowiednią wymową, materiały do samodzielnego uczenia 
się języka obcego dla dzieci i młodzieży, słowniki, przykłady referatów i wypracowań w języku obcym. Dodatkowo, na blogu są zamieszczone materiały wideo oraz materiały dźwiękowe, które usprawniają proces uczenia się języka obcego. Autor bloga może zamieszczać również swoje praktyczne porady dotyczące słownictwa i odpowiedniej wymowy $\mathrm{w}$ określonym języku obcym oraz zasady stosowania gramatyki. Taki rodzaj bloga, o atrakcyjnej dla młodzieży oprawie graficznej, z pewnością jest cennym narzędziem skupiającym wiele środków dydaktycznych, które mogą zostać wykorzystane nie tylko w samokształceniu, ale i w procesie nauczania/uczenia się. Przykładem bloga prowadzonego przez doświadczonego lektora jest „Blog o języku niemieckim”"1.

Kolejnym przykładem bloga o walorach edukacyjnych jest blog, którego główną tematyką może stać się propagowanie wykorzystywania metody projektów w realizacji procesu nauczania/uczenia się. Autor na swoim blogu proponuje stosowanie metody projektów w nauczaniu przedmiotów ścisłych, takich jak fizyka i matematyka, przez swoich uczniów. Blog pełni zatem miejsce zamieszczania roboczych wersji projektów przygotowanych przez podmioty uczące się w ramach konkretnych lekcji. Dzięki temu pozostali uczniowie mogą wyrażać swoje opinie i korygować ewentualne błędy bądź też dzielić się nowymi pomysłami rozwiązań. Dodatkowym walorem takiego rodzaju bloga jest szczegółowe zapoznanie uczniów z metodą projektów, dzięki czemu młodzi ludzie mogą swobodnie ją stosować, realizując różne projekty nie tylko z przedmiotów ścisłych, ale i również humanistycznych. Autor bloga, promując wykorzystywanie metod problemowych, zamieszcza na blogu szereg przydatnych informacji niezbędnych do prawidłowego wykonania projektów. Stosowanie metody projektów w różnych dziedzinach nauki jest bardzo korzystne dla uczniów. Nie tylko uczy ich wzajemnej współpracy, ale przede wszystkim pozytywnie wpływa na rozwój zainteresowań i twórczość młodych jednostek, umiejętność rozwiązywania prostych i złożonych problemów, organizowania pracy własnej i jej krytycznej oceny. Metoda ta nawiązuje do tradycyjnej metody projektów sformułowanej przez Williama H. Kilpatricka. Przykładem bloga, który promuje stosowanie metody projektów w edukacji, jest blog „Projekty uczniów ZSEEiM w Bielsku Białej”12.

W przestrzeni wirtualnej można również odnaleźć blogi specjalizujące się w określonej dziedzinie. Jednym z takich blogów jest blog w całości poświęcony kognitywistyce. Autor zamieszcza tam artykuły naukowe i popularnonaukowe,

\footnotetext{
${ }^{11}$ Więcej: http://blog.tyczkowski.com/.

${ }^{12}$ Więcej: http://www.projekty.hojnacka.net/.
} 
ciekawostki naukowe, opinie z polskich ośrodków badawczych w obrębie kognitywistyki dotyczące efektywnego przyswajania informacji i metod efektywnego uczenia się oraz e-learningu. Zamieszczone na blogu wpisy są napisane prostym, zrozumiałym językiem, bez naukowego żargonu, dzięki temu są przystępne dla osób, które nie znają specjalistycznej psychologicznej terminologii. Skomplikowane treści zostają natomiast wzbogacone atrakcyjnymi grafikami i interesującymi filmami. Takie narzędzie może być bogatym źródłem informacji o kwestiach psychologicznych, w szczególności dla tych osób, które dopiero rozpoczynają studiowanie literatury z tej dziedziny. Przykładem bloga specjalizującego się w konkretnej dziedzinie nauki jest blog „Mechnika umysłu”"13.

Te nieliczne przykłady blogów internetowych o walorach edukacyjnych, które można $\mathrm{z}$ łatwością odnaleźć w przestrzeni wirtualnej, jednoznacznie wskazują, iż współcześnie blogi zyskują nowe znaczenie. Stają się one praktycznym narzędziem dydaktycznym wykorzystywanym przez nauczycieli w procesie nauczania/uczenia się w celu jego wzbogacenia, a także pobudzania motywacji uczniów do pogłębiania swojej wiedzy i aktywnego uczestnictwa w społeczeństwie informacyjnym.

Wspieranie uczniów w wykorzystywaniu nowych technologii i ich możliwości w procesie uczenia się i samokształcenia jest kluczowym zadaniem nauczyciela, który realizując rolę dydaktyczno-wychowawczą, powinien przede wszystkim przygotować młodą jednostkę do całożyciowego uczenia się, a także do właściwego poszukiwania, selekcjonowania oraz przetwarzania informacji ( $w$ tym tych dostępnych w Internecie).

Idea kształcenia ustawicznego wymaga posługiwania się różnymi narzędziami, w szczególności tymi, które stają się dla uczniów przydatne, praktyczne i przede wszystkim atrakcyjne. Bez wątpienia, blogi internetowe spełniają te trzy kryteria, ważne z punktu widzenia młodych jednostek.

\section{Literatura}

Bereźnicki F. (1987). Dydaktyka ogólna w zarysie. Szczecin.

Bereźnicki F. (2011). Podstawy kształcenia ogólnego. Kraków.

Hoffman P.E. (1995). Internet. Warszawa.

Okoń W. (1987). Wprowadzenie do dydaktyki ogólnej. Warszawa.

Siuda P. (2013). (Nie) bój się bloga! Jak wykorzystywać blog w edukacji? Gdańsk.

Wawrzak-Chodaczek M. red. (2008). Komunikacja społeczna w świecie wirtualnym. Torun.

${ }^{13}$ Więcej: http://www.mechanikaumyslu.pl/. 
Źródła internetowe:

Hendzel J., Uczymy się blogując?, „e-mentor” 2007, nr 4(21); http://www.e-mentor.edu.pl/ artykul/index/numer/21/id/455 (dostęp: 03.01.2014 r.).

Jeleśniański M., Liczba blogów w Polsce i na świecie - czy da się ja określić?; http://eredaktor.pl/ internet-badania-trendy/liczba-blogow-w-polsce-i-na-swiecie-czy-da-sie-ja-okreslic/ (dostęp: 03.01.2014 r.).

Meger Z., Nowe narzędzia edukacyjne w sieciach społecznościowych; http://www.e-edukacja.net/ osma/referaty/Sesja_2b_2.pdf (dostęp: 05.01.2014 r.).

\section{The New Uses of Weblogs. Evolving Towards Didactic Functions}

\section{Summary}

Internet is currently the world's largest database with unlimited access to information in various fields, which is becoming increasingly important at various levels of education. The Internet is now becoming a limitless source of knowledge and possibilities as well as a didactic tool that is used by both students and teachers who want to enrich and optimize the education process.

Online information is increasingly becoming a complementary source of content knowledge that is transmitted by the teachers during lessons but it also goes beyond the scope of standard curriculum. Most of all, it is presented in a form that is approachable to young people. Interesting images, animations and videos significantly affect students' interest in the topic, expanding their knowledge, instilling cognitive motivation and becoming the means of hands-on practice in the processes of the acquisition of new content, revision and repetition of already acquired content.

The use of new technologies by teachers in the educational process should be the answer to the needs of young people for whom the virtual space has now become their "natural environment" where they look for cyberfriends, spend their free time, share ideas and achievements but also acquire various kinds of information and knowledge about the world.

Every year the Internet offers an increasing number of websites, platforms, forums, fan sites, whose main theme is widely understood education. These are special places in the virtual space from which one can draw information on modern school, school curricula at different levels of education as well as benefiting from a rich database of teaching resources, especially lesson plans, exercises, games and educational videos, guides for teachers and students. Blogs that initially played the role of online diaries are becoming increasingly popular among children, adolescents and adults. However, the ease of setting up and using blogs on an everyday basis, publishing posts, attaching videos, sounds and animations resulted in a situation where currently there is a very large number of blogs on all sorts of subjects. This, in turn, has led to the formation of a specific kind of network, so-called blogosphere, which is made up of the interconnections between blogs.

In education a blog fulfils a number of specific roles. First of all, it combines two important elements in the development of young people - education and entertainment. Using these advantages of blogs in education can have positive impact on the attitude of students to the learning process and to 
the stereotypical image of a teacher, turning him or her into a person who accepts technological novelties and "moves with the times" as well as knowing how to use these novelties in practice.

Together with their development, blogs and their content also began to perform certain functions, including informing function, entertainment, communication, opinion-making, marketing, integrating, and also the function of education, which, in recent years, has been increasingly implemented in both the student as well as teacher environment. Moreover, more and more blog authors, so-called bloggers, are the teachers and academic lecturers themselves who want to enrich not only their own working methods as well as developing competence in the new media, but most of all, they want to encourage students to active participation in the teaching-learning process.

In addition, blog as a bilateral communication tool enables continuous communication between the teacher and the student, becoming an opportunity to get to know the students better and above all, to learn about their interests, hobbies and individual as well as collective needs and expectations. The blog is also becoming a platform for the exchange of ideas between the teacher and the students. This creates the opportunity not only to exchange information on the schedule, work plan, the credit requirement for a specific class, the content of homework and extra assignments, but the blog is also becoming a great place to spark interesting discussions around the topics discussed during the lesson and moving the debate beyond the school building. For students it is the more attractive as they do not have to assume a specific, traditional and rigid role, but feel at ease and less formal. It creates the possibility of getting a more creative opinion, ideas and judgments on the subject. Moreover, this is a great opportunity for the students who fear public speaking or who are shy. Communication via blogs gives them some sort of freedom, an opportunity to reflect on their own statements.

A blog can also play an integrating role for the school community. It allows for the creation of school or class yearbook, where one can post brief reports from field trips, residential trips, competitions as well as attaching photos and videos of the most important class or school events.

A blog can also have a supporting role in teaching more difficult subjects, such as mathematics, physics, chemistry, but also the subjects covering the liberal arts, including history, Polish or a foreign language. Presenting complex mathematical formulas, chemistry experiments, poems and short stories with coloured images, animations, videos or hypertext can arouse students' natural need for cognitive development and trigger their internal motivation to continue the search for information in a specific area.

An additional advantage of blogs is that they allow us to repeatedly return to the content that is of our interest, replay it, classify it and present it in a proper way. At a convenient time the student can use the information that will enable him or her to deepen the previously acquired knowledge, memorise it or revise it. This plays a significant role in the educational process as it systematises students' knowledge.

Nowadays, the virtual space offers a variety of educational blogs. These are blogs that focus primarily on exposing specific educational values and they are written by the teachers. For example, a popular form of foreign language teaching is to create language blogs in which the author, as an experienced tutor, attaches useful tips on grammar, vocabulary and pronunciation, thus helping in foreign language learning. Another example of a blog with educational values is a blog focusing on the promotion of the use of the project method, which is very beneficial for students, in the process of teaching-learning. This creates the possibility of solving problem situations which take the form of simple and complex problems, teach cooperation and creative thinking. 
In the virtual space, one can also find blogs that specialize in specific areas. One such blog is entirely devoted to cognitive science. The author of the blog posts scientific papers and popular-science articles, curiosities from the world of science, scientific opinions of Polish research centres on aspects regarding cognitive science, methods of effective learning and e-learning. As a result, younger individuals may derive reliable information on the fields of science which interest them.

An important task facing the school and the teacher is the task of introducing young people to the information society, familiarizing them with new technologies and methods of their use in the process of learning and self-education.

The idea of lifelong learning requires the use of different tools, in particular those that are useful for students, practical and above all attractive. Without a doubt, blogs fulfil these three criteria. 